\title{
Three-Dimensional Modeling of Spatial Reinforcement of Soil Nails in a Field Slope under Surcharge Loads
}

\author{
Yuan-de Zhou, ${ }^{1}$ Kai Xu, ${ }^{2}$ Xinwei Tang, ${ }^{3}$ and Leslie George Tham ${ }^{4}$ \\ ${ }^{1}$ State Key Laboratory of Hydroscience and Engineering, Department of Hydraulic Engineering, \\ Tsinghua University, Beijing 100084, China \\ ${ }^{2}$ Nanjing Hydraulic Research Institute, 223 Guangzhou Road, Nanjing 210029, China \\ ${ }^{3}$ School of Civil Engineering and Transportation, South China University of Technology, Guangzhou 510640, China \\ ${ }^{4}$ Department of Civil Engineering, The University of Hong Kong, Pokfulam Road, Hong Kong
}

Correspondence should be addressed to Xinwei Tang; cttangxw@scut.edu.cn

Received 7 June 2013; Accepted 14 August 2013

Academic Editor: Fayun Liang

Copyright (C) 2013 Yuan-de Zhou et al. This is an open access article distributed under the Creative Commons Attribution License, which permits unrestricted use, distribution, and reproduction in any medium, provided the original work is properly cited.

Soil nailing has been one of the most popular techniques for improving the stability of slopes, in which rows of nails and a structural grillage system connecting nail heads are commonly applied. In order to examine the spatial-reinforcement effect of soil nails in slopes, a three-dimensional (3D) numerical model has been developed and used to back-analyze a field test slope under surcharge loading. Incremental elastoplastic analyses have been performed to study the internal deformation within the slope and the development of nail forces during the application of top surcharge loads. Different treatments of the grillage constraints at nail heads have been studied. It is shown that the numerical predictions compare favorably with the field test measurements. Both the numerical and the field test results suggest that soil nails are capable of increasing the overall stability of a loose fill slope for the loading conditions considered in this study. The axial force mobilization in the two rows of soil nails presents a strong dependence on the relative distance with the central section. With the surcharge loads increased near the bearing capacity of the slope, a grillage system connecting all the nail heads can affect the stabilizing mechanism to a notable extent.

\section{Introduction}

Soil nailing is an effective in situ reinforcing technique for retaining excavations and stabilizing slopes. The interaction between a soil nail and the surrounding soil is a key aspect in the design and therefore is of great interest to both engineers and researchers. Soil nails used in slope upgrading works normally consist of an unstressed steel bar grouted in a predrilled hole of soil mass using cement slurry and are usually designed as a passive reinforcement in that resisting axial force is mobilized only when slope instability is triggered by extreme loading. The primary resisting force comes from the tensile resistance of the steel reinforcement. The interaction mechanism is characterized by the mobilization of frictional forces along the entire length of the inclusion, which consequently results in the generation of tensile forces along the reinforcement. Quite several analytical models [1-5] have been developed and used to qualitatively describe the principal mechanism, which are easy to use but may oversimplify the complex stress transfer mechanism.

Numerical simulation is also an important method for investigating the soil nail behavior. Two-dimensional modeling has been commonly applied to simulate the fundamental behavior of soil-nail interactive system as a plane strain problem, such as those by Matsui et al. [6], Cheuk et al. [7], and Fan and Luo [8]. These studies focused on different aspects of soil-nail system, including the force transfer mechanism, soilnail interaction, and failure mechanism. 3D modeling studies have been also applied by researchers to analyze fundamental behavior of nailed slopes. Zhang et al. [9] and Yang and Drumm [10] analyzed 3D slope behavior to investigate the effects of stage excavation, construction, and the surcharge loading. In addition, Zhou [11] studied the boundary effect on the pullout resistance and the pullout reaction of soil nails in a pullout test box using 3D numerical models. A thorough 3D numerical investigation into the reinforcement effect of 
multiple soil nails in slopes under varied working conditions is still limited.

$\mathrm{Li}$ [12] reported a field slope test to examine the strengthening mechanism of soil nails in a purposely built fill slope under different loading conditions. Typically top surcharge and water infiltration from the slope surface as well as the bottom were considered. The test results demonstrated a global stabilizing effect by the multiple soil nails. Detailed records of the slope movements, the nail force distributions, and the change in water content distributions were provided [12]. This paper describes a 3D numerical model for the investigation of the complex interaction between nails and surrounding soils in this slope test. The response in the surcharge process was focused in this study as significant nail forces were mobilized in this stage. Different to the previous research by the authors [13], the coupled hydromechanical response in the test slope is modeled based on a 3D finite element model in this study, in which the spatial reinforcement by two rows of soil nails is considered. An interface element technique is adopted to simulate the cohesive-frictional behavior along the soil-nail interface. The contribution of the surface grillage beams connecting the nail heads has been also examined through a series of numerical analyses. The numerical results are compared with the field measurements to assess the reinforcement effect of each soil nail in the designed arrangement manner, and the mechanism of nonuniform distribution of nail force mobilization has been also studied.

\section{Briefs about the Field Test}

2.1. Slope Construction and Geometry. For completeness, a brief introduction to the field test is provided in this section. More details about the field test can be found elsewhere [12]. The test slope is made up of loose completely decomposed granite $(\mathrm{CDG})$ and was constructed on a moderately gentle site with an average gradient of $20^{\circ}$. The basic geometry of the slope is given in Figure 1. It was $4.75 \mathrm{~m}$ in height and $9 \mathrm{~m}$ in width. The crest of the slope is $4 \mathrm{~m}$ long, and the inclination angle is $33^{\circ}$. In order to laterally confine the fill soils, two gravity retaining walls were constructed on both sides, and an apron of $0.8 \mathrm{~m}$ in height was built at the toe. A blinding layer was placed underneath the fill slope to isolate it from the ground soil and to provide a drainage path for water infiltration during the wetting stages of the field test. It was constructed by ordinary concrete and reinforced by A252 steel mesh, and a layer of no-fines concrete was arranged above.

Ten cement grouted nails were installed in the test slope for the purpose of stabilization at vertical and horizontal spacings of $1.5 \mathrm{~m}$. All the nails were arranged at an inclination angle of $20^{\circ}$ to the horizontal. Similar to common practice, the construction procedures were as follows: firstly a hole of $100 \mathrm{~mm}$ in diameter was drilled; then a $25 \mathrm{~mm}$ diameter steel ribbed bar was inserted into the hole with centralizers to fix the position; at the last step, the hole was filled with ordinary cement slurry. In the field tests, two types of nail heads were applied, namely, independent head and grillage beams, which allowed an investigation into the influence of different treatments.
2.2. Field Surcharge Test. The field test study was comprised of three stages, namely, (1) surcharge, (2) wetting with surcharge, and (3) wetting without surcharge. For the main attention of this study is placed on the strengthening mechanism of multiple nails, only the surcharge loads during the first stage are described herein. The top surcharge was achieved by layering concrete blocks of $1 \mathrm{~m} \times 1 \mathrm{~m} \times 0.6 \mathrm{~m}$ on the slope crest (Figure 1). A total of 90 blocks were applied sequentially into 5 layers along the vertical direction. The development of resultant pressure from the self-weight of blocks on the central area of the crest can be categorized into 4 main stages (Figure 2), and the final total surcharge pressure was $72 \mathrm{kPa}$. During the field test, a comprehensive instrumentation system, including inclinometers, strain gauges, moisture probes, and tensiometers, was designed and installed in the fills and nails (Figure 1). The field measurement data formed the basis of the parametric analyses and discussions in this study.

\section{Numerical Model}

The field test data showed that the slope fills remained unsaturated during the surcharge stage. Even though the contribution of the suction to the overall response of the nailed slope has been demonstrated to be negligibly small by the previous plane strain analyses [13], a coupled hydromechanical numerical approach is adopted in this study for the consideration of consecutive modeling of the complete three stages in the field test. The finite element package ABAQUS [14] is used as a platform for the analyses. The current study adopts exactly the same basic assumptions as described in detail in [13]. Here we will just briefly outline the principles of this numerical model. The loose fill is treated as a porous medium, and a simplified effective stress principle is adopted to describe its mechanical behavior:

$$
\bar{\sigma}=\sigma-\chi(s) u_{w} \mathbf{I},
$$

where $\bar{\sigma}$ and $\sigma$ are the effective and total stresses, respectively; $\chi$ is a factor that depends on the saturation degree $s$; $\mathbf{I}$ is a second-order unit tensor; $u_{w}$ denotes the pore water pressure. As a common choice, a simple function of $\chi=s$ is adopted in this study.

3.1. Basic Equations. The fundamental equations include stress equilibrium of the soil skeleton and flow continuity of pore water, which are given as follows:

$$
\begin{aligned}
\int_{V}\left(\bar{\sigma}+\chi u_{w} \mathbf{I}\right): \delta \boldsymbol{\varepsilon} d V= & \int_{s} \mathbf{t} \cdot \delta \mathbf{v} d S+\int_{V} \mathbf{f} \cdot \delta \mathbf{v} d V \\
& +\int_{V} s n \rho_{w} \mathbf{g} \cdot \delta \mathbf{v} d V \\
\frac{d}{d t}\left(\int_{V} \frac{\rho_{w}}{\rho_{w}^{0}} s n d V\right)= & -\int_{s} \frac{\rho_{w}}{\rho_{w}^{0}} s n \mathbf{n} \cdot \mathbf{v}_{w} d S,
\end{aligned}
$$

where $\delta \boldsymbol{\varepsilon}=\operatorname{sym}(\partial \delta \mathbf{v} / \partial \mathbf{x})$ denotes the virtual rate of deformation; $\delta \mathbf{v}$ is a virtual velocity field; $\mathbf{t}$ and $\mathbf{f}$ denote surface tractions per unit area and body forces per unit volume, respectively; $n$ indicates the soil porosity; $\mathbf{g}$ is the gravitational 


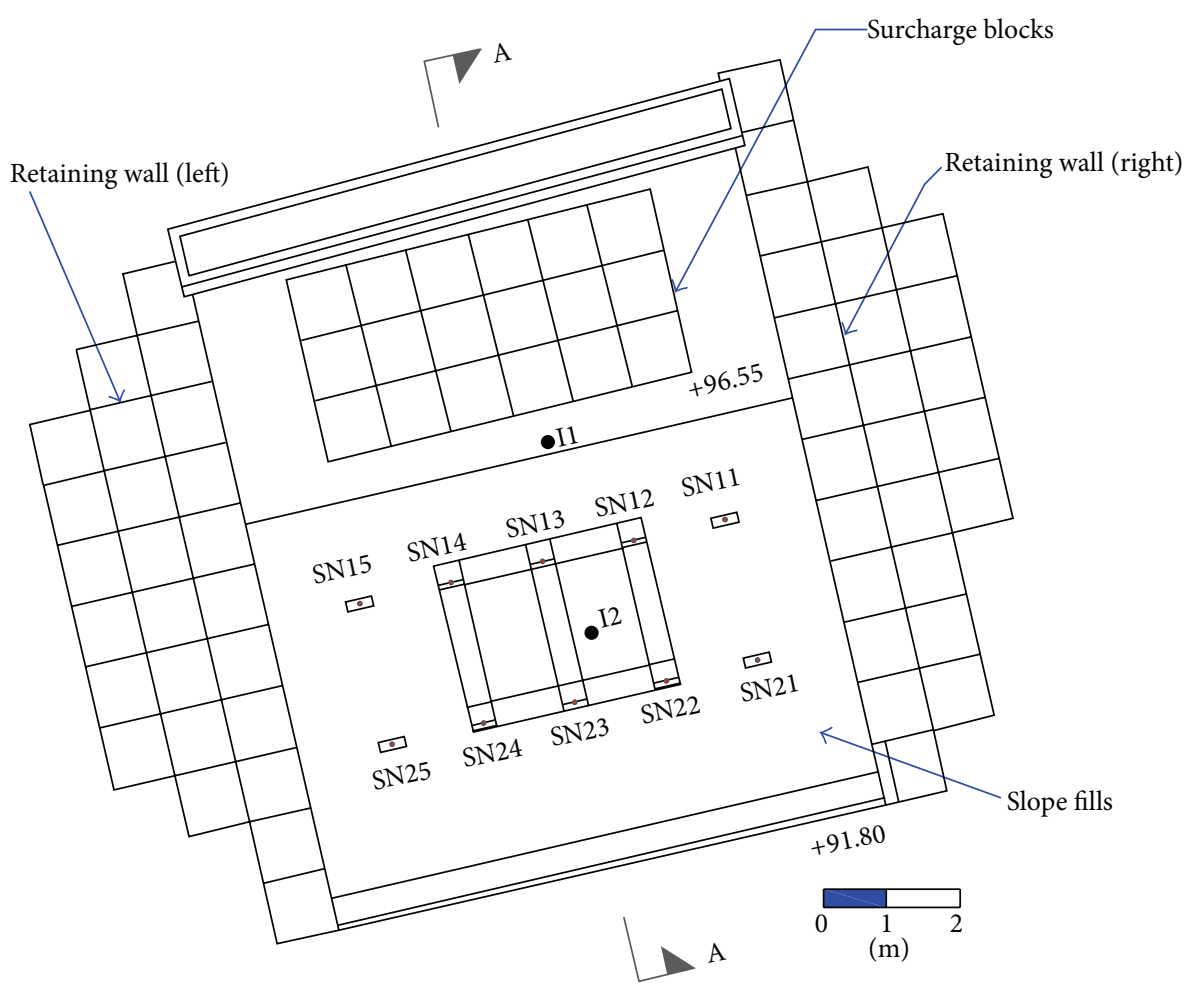

(a) Plan view

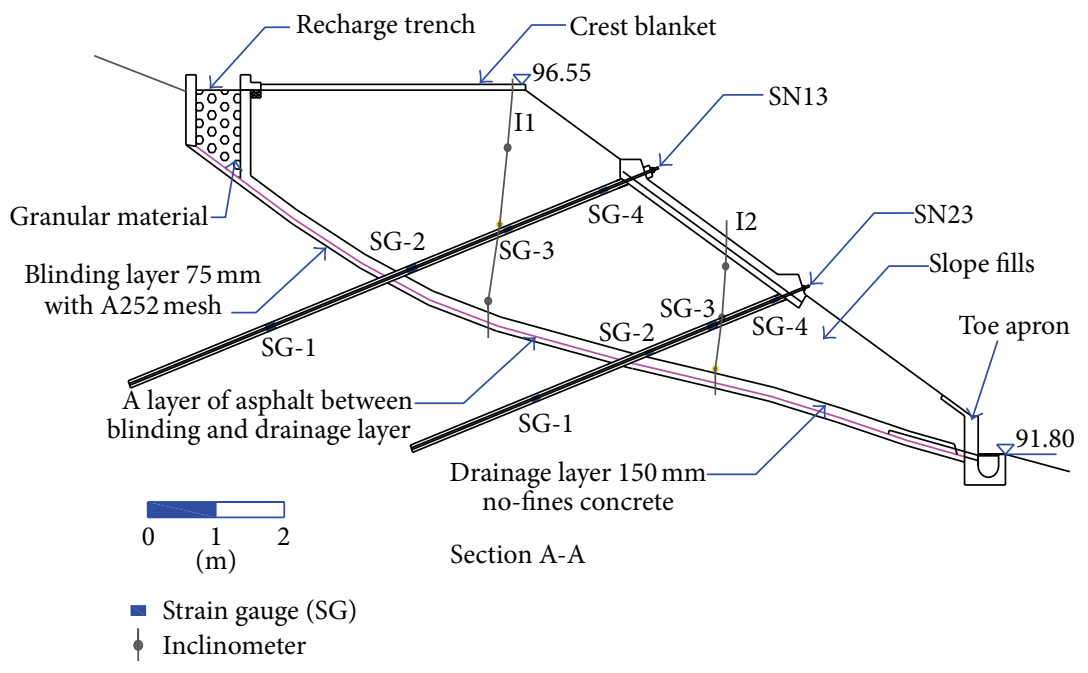

(b) Section view

FIGURE 1: General arrangement of the field test.

acceleration; $\mathbf{v}_{w}$ is the pore water flow velocity; $\mathbf{n}$ is the outward normal to $S ; \rho_{w}$ and $\rho_{w}^{0}$ denote the water density and a reference density for normalization, respectively.

The coupling stress equilibrium and flow continuity equations are solved simultaneously. A Lagrangian formulation is used in the discretization of the balance equation for the soil skeleton, and displacements are taken as nodal variables. The continuity equation is integrated in time using the backward Euler approximation method, and pore water pressure is taken as a field variable in finite element discretizations.
Generally nonlinearity arises from the coupling between seepage and mechanical behavior in the system equations. The Newton-Raphson method is used to calculate the incremental numerical solutions. In addition, Darcy's Law is applied to model the pore fluid flow, which has been shown to be valid for unsaturated soils if the coefficient of permeability, $\mathbf{k}$, is written as a function of the degree of saturation.

3.2. 3D Finite Element Mesh and Boundary Conditions. The symmetry of the nailed slope and load/boundary conditions 
TABLE 1: Summary of material parameters.

\begin{tabular}{|c|c|c|c|c|}
\hline & Initial conditions & Elastic properties & Shear strength & Hydraulic properties \\
\hline CDG fill soil & $\begin{array}{c}\gamma_{d}=1.41 \mathrm{~kg} / \mathrm{m}^{3} \\
e_{0}=0.86 \\
M_{c 0}=14.9 \%\end{array}$ & $\begin{aligned} \mu & =0.05 \\
\kappa & =0.011\end{aligned}$ & $\begin{array}{c}c^{\prime}=2 \mathrm{kPa} \\
\phi^{\prime}=32^{\circ} \\
\psi=5^{\circ}\end{array}$ & $\begin{array}{c}\text { k-Figure } 4 \\
\text { SWCC-Figure } 4\end{array}$ \\
\hline Soil nails & 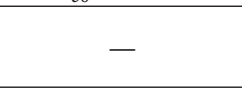 & $\begin{array}{c}E=2.5 \times 10^{4} \mathrm{MPa}, \\
\mu=0.2\end{array}$ & 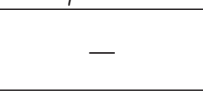 & - \\
\hline In situ ground & - & $E=35 \mathrm{MPa}, \mu=0.25$ & - & - \\
\hline No-fines concrete & - & $\begin{array}{c}E=1 \times 10^{4} \mathrm{MPa} \\
\mu=0.2\end{array}$ & - & $k=1.0 \times 10^{-4} \mathrm{~m} / \mathrm{s}$ \\
\hline Soil-nail interface & - & $\begin{array}{c}E=10 \mathrm{MPa} \\
\mu=0.2\end{array}$ & $\begin{array}{c}c^{\prime}=10.6 \mathrm{kPa} \\
\phi^{\prime}=35.8^{\circ}\end{array}$ & - \\
\hline
\end{tabular}

$E, \mu, \kappa, M_{c 0}, \gamma_{d}, e_{0}, k, c^{\prime}$, and $\phi^{\prime}$ are Young's modulus, Poisson's ratio, the slope of the unloading-reloading line on the $\nu-\ln p^{\prime}$ diagram, initial moisture content, dry density, initial void ratio, permeability coefficient, cohesion intercept, and internal friction angle, respectively, and the subscript " 0 " denotes the initial value.

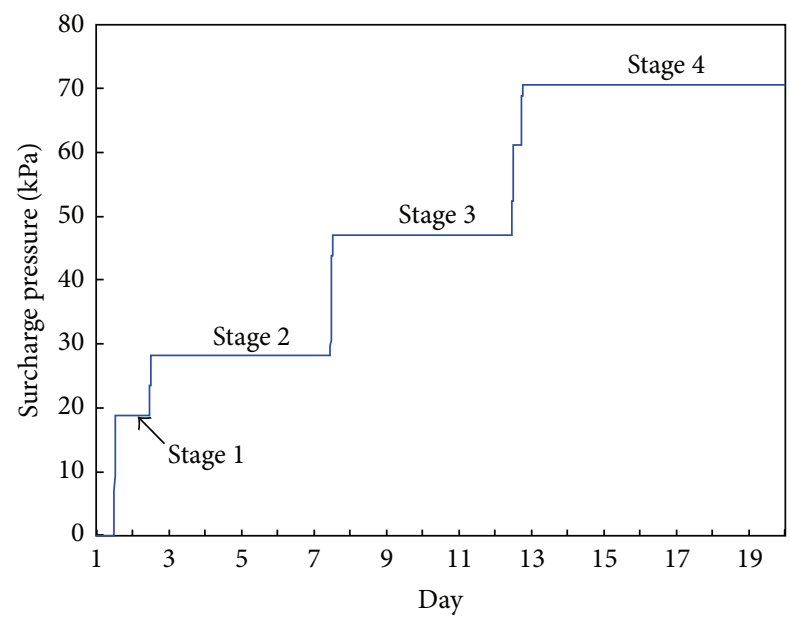

FIGURE 2: The applied surcharge process during the field test.

allows only one half of the slope to be modeled. The finite element mesh is set up according to the actual geometry of the slope and the soil nails. As shown in Figure 3, the slope fills and the ground soil are modeled using a finite element mesh consisting of 114815 8-node linear solid elements. Each node has four degrees of freedom, one for pore water pressure and three for displacements. Since a layer of asphalt was applied above the natural ground surface as a watertight measure in the field test, it is assumed in this study that redistribution of water content is negligible within the in situ ground. Hence only displacements are taken as the field variables for the ground soil in the model. The drainage layer (i.e., no-fines concrete layer) is also simulated as a deformable porous medium by solid finite elements with coupled nodal variables. Regarding the soil nails, each steel bar and surrounding grout are idealized as a cylindrical bar of the same diameter and are represented by solid elements with only displacement variables (see the inset of Figure 3).

The displacement boundary conditions of the numerical model are taken as vertical rollers on the left cutting edge and the right side of the test slope and full fixity at the base and the constrained region at the concrete apron near the toe. Since

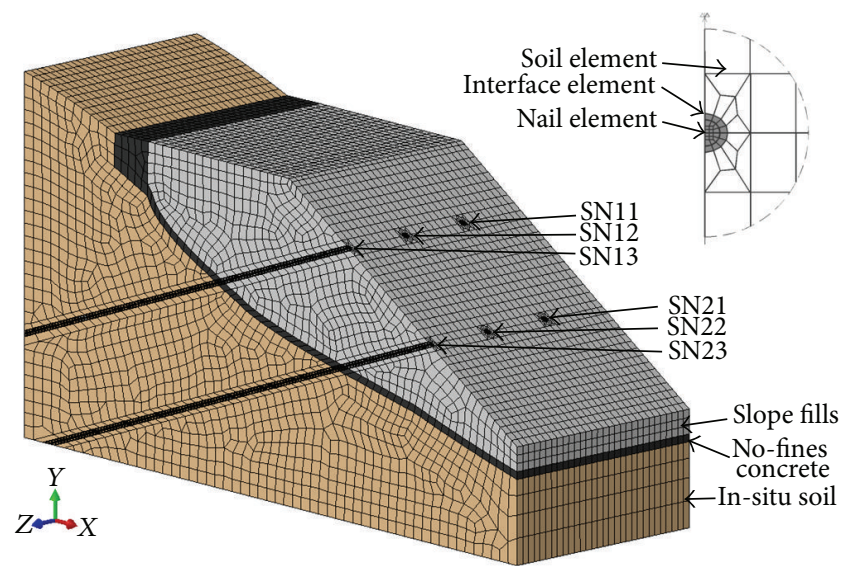

FIGURE 3: Finite element model of the nailed test slope (the inset figure shows the detailed modeling of soil-nail interaction).

no water could flow out from the unsaturated slope during the surcharge process, no-flow conditions are assumed along the outer boundary of the entire model. Moreover, the interfaces between the no-fines concrete layer and the surrounding soils are assumed to be continuous with no slippage allowed as a deep-seated failure mechanism along the interfaces was not observed in the field test.

The average void ratio and degree of saturation of the soil measured prior to the field test have been adopted as the initial conditions for the analyses (Table 1). The initial distributions of internal stresses and pore water pressures within the slope under the gravity loads are then obtained by initial equilibrium calculations before surcharge loading is imposed on the slope. The surcharge is simplified as a uniformly distributed pressure applied to the crest of the slope, as prescribed by the covering area of the concrete blocks during the field test.

3.3. Soil Models and Parameters. As in previous plane strain study [13], the fill soils are modeled by the Mohr-Coulomb plasticity model with a nonassociated flow rule. To represent the stress-dependent stiffness property of typical residual 


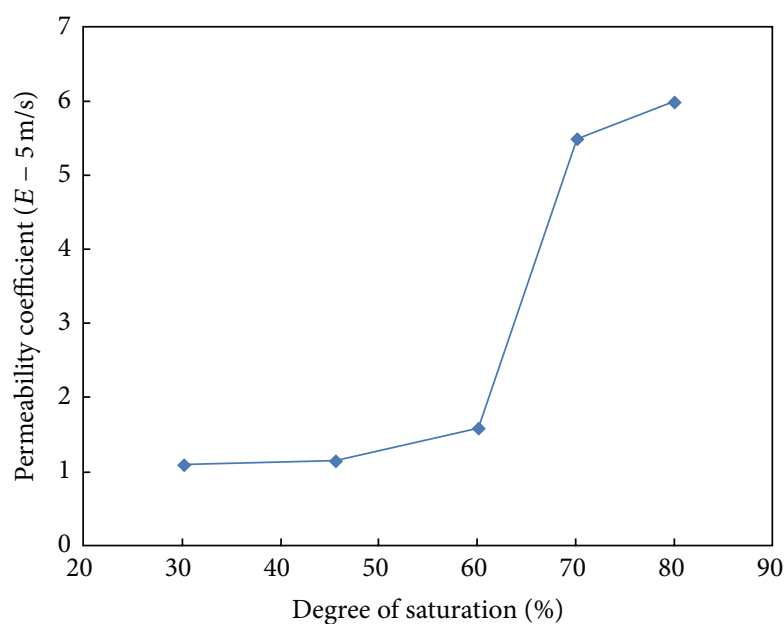

(a) Permeability coefficient versus degree of saturation

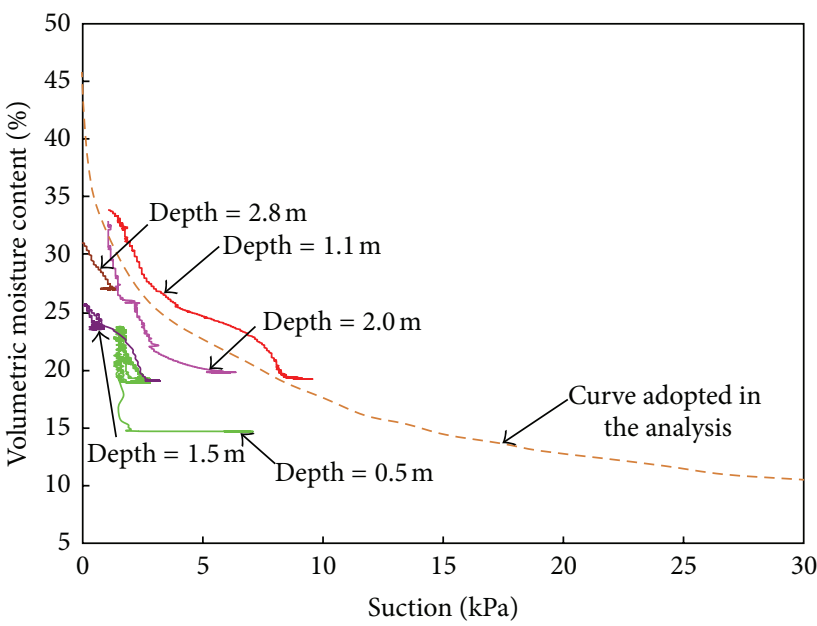

(b) Water retention curve (solid lines denote field measurements)

Figure 4: Hydraulic properties of the CDG fill soil.

soils, the bulk modulus, $K$, of the soil skeleton is defined as a function of the mean effective stress, $p^{\prime}$, according to

$$
K=\frac{\partial p^{\prime}}{\partial \varepsilon_{v}^{e}}=\frac{1+e}{\kappa} p^{\prime}=\frac{v}{\kappa} p^{\prime},
$$

where $\varepsilon_{v}^{e}$ denotes the elastic volumetric strain, $e$ and $\nu$ are the void ratio and the specific volume, respectively, and $\kappa$ is the slope of the recompression-unloading line on the $v-\ln p^{\prime}$ diagram. The Poisson ratio, $\mu$, is assumed to be a constant, and the shear modulus, $G$, is calculated by

$$
G=\frac{3(1-2 \mu) \nu p^{\prime}}{2(1+\mu) \kappa} .
$$

A smooth flow potential function proposed by Menétrey and Willam [15] is adopted in the model. It has a hyperbolic shape in the meridional stress plane and a piecewise elliptic shape in the deviatoric stress plane. Generally plastic flows in the meridional and deviatoric planes are nonassociated, and dilatancy can be controlled by the magnitude of the dilation angle. A perfect plastic hardening law is applied in the following analyses.

Table 1 summarizes the parameters adopted in the analyses. The stiffness and strength parameters are obtained from relevant experiments [12]. A small dilation angle value of $\psi=$ $5^{\circ}$ is taken to limit shear-induced volumetric expansion in the loose fill.

Regarding the hydraulic behavior of the unsaturated soil, Figure 4 presents the permeability function and the water retention curve for the loose fill soil, which are obtained based on the observations from laboratory tests and field measurements. The initial compaction degree of the loose fill was $\sim 75 \%$ of the maximum dry density measured in a standard Proctor test, and the initial moisture content was $14.9 \%$.

For the in situ ground and the no-fines concrete layer underneath the fill slope, the field test data showed that their deformation is small enough that they are modeled by a linear elastic model with the model parameters given in Table 1. A large coefficient of permeability, $k=10^{-4} \mathrm{~m} / \mathrm{s}$, is taken for the no-fines concrete layer to represent its nearly free-draining property.

3.4. Modeling of Soil Nails. As described above, each soil nail is idealized as an elastic homogeneous bar in the finite element model considering the low possibility of steel yielding. By assuming the compatibility of axial deformation between the grout and the steel rod along the nailing direction, the equivalent Young's modulus $(\widetilde{E})$ of the nail elements is determined as follow:

$$
\widetilde{E}=\frac{E_{r} A_{r}+E_{g} A_{g}}{A_{r}+A_{g}},
$$

where $E_{r}$ and $E_{g}$ denote the elastic modulus of the steel rod and the grout, respectively, and $A_{r}$ and $A_{g}$ are their crosssectional area, respectively.

It has been demonstrated that a modeling approach that is capable of accounting for possible bond and slippage between the soil nail and the surrounding soil is more suitable for the analysis of nail reinforcement effect and the global behavior of the nailed slope [13]. Hence an interface element technique has been adopted in this study. Three-dimensional eightnode interface elements are used to simulate the steel-grout interfacial behavior. As in many previous analyses by other researchers (such as [16]), the elastic stiffness parameters, $k_{n}$ and $k_{s}$, for the grout-soil interface are defined as $E_{s} / t$ and $G / t$ respectively, where $t$ is the thickness of interface elements; $E_{s}$ and $G$ are the Young and shear moduli of the surrounding soil material, respectively. Herein $t$ is chosen to be $2 \mathrm{~mm}$, that is about 2 percent of the nail diameter, and it can be considered to be negligibly small with respect to the nail size.

The Mohr-Coulomb shear model is taken as the failure criterion along the nail-soil interface. Tangential slippage will 
occur when the mobilized shear stress, $\tau$, reaches the shear strength given by

$$
\tau=c+\sigma_{n}^{\prime} \tan \phi,
$$

where $c$ is an equivalent cohesion parameter for the soil-nail interface; $\phi$ is the friction angle; and $\sigma_{n}^{\prime}$ denotes the effective normal stress exerted on the interface.

The frictional properties of the soil-nail interface are evaluated from pullout tests prior to the field tests. This gives the apparent cohesion intercept and equivalent friction coefficient of $10.6 \mathrm{kPa}$ and $0.72\left(35.8^{\circ}\right)$, respectively. The offdiagonal terms in the elastic stiffness matrix are zero, and hence no dilatancy along the interface is considered in the elastic regime. The dilatancy is introduced after the failure criterion has been reached. The flow potential function is of a similar form as (6) with the friction angle replaced by the dilation angle $\psi$. A summary of the above mechanical parameters for the soil-nail interface is listed in Table 1.

In addition to the interfacial behavior along the soil-nail interface, the boundary conditions at the nail heads also have a direct impact on the nail force mobilization. There are two different constraint options for the nail heads at the slope surface. The first choice is a free end condition, which represents a soil nail without any nail head or facing structure. Alternatively, the nail heads are pinned together using a technique of multiple point constraint, which presumes that the grillage beams made up of reinforced concrete material are strong enough and the displacements of the connecting nail head nodes are enforced to be equal. It should be noted that no interaction between the grid structure and the surface soil in contact has been considered.

3.5. Analysis Programme. A total of four analyses have been conducted in this study, and the analysis conditions are given in Table 2. The surcharge loading process is considered in all the analyses on a real-time scale over a period of $\sim 20$ days (Figure 2). Different considerations about the surface constraint have been examined to identify the spatial reinforcement effect of soil nails on the overall response of the field test slope. Besides an assumed case of unreinforced slope, another hypothetical case of the test slope with all the heads of soil nails connected has also been considered to illustrate the possible maximal contribution by the surface structure. All the analysis cases are deemed to form a basis of comparison to examine the stabilizing mechanisms of multiple soil nails in slopes.

\section{Results and Discussions}

4.1. Internal Slope Movement. During the field test, two inclinometers were installed in the slope near the central section, denoted as I1 for the one at $300 \mathrm{~mm}$ from the crest corner and $\mathrm{I} 2$ for the one installed in the middle (Figure 1). Three sensors were installed on each inclinometer, and the horizontal displacements in the down-slope direction were monitored. Figures 5 and 6 compare the predicted and measured horizontal displacements at the two inclinometer positions at different surcharge stages. The predictions for an assumed
TABLE 2: Summary of the analysis cases.

\begin{tabular}{lcc}
\hline Cases & Soil nails & Grillage system \\
\hline 1 & Yes & No \\
2 & Yes & 4 nails heads (SN12, SN13, \\
& & SN22, SN23) constrained \\
3 & Yes & All 6 nails heads \\
4 & constrained \\
\hline
\end{tabular}

case with all nail heads connected by grillage (case 3 ) and for an unreinforced slope (case 4) are also shown for comparison. The three nailed slope models with different assumptions of the surface grillage effect give very similar deformation patterns, which are also similar to those observed in the field test, except that the magnitude of the predicted movements at I2 location is smaller. The relatively small soil movements at I2 predicted by the numerical model can be mainly attributed to the simplifications made in the modeling of surface grid structure, which only consider the constraint effect of translational displacement at the nail heads, whilst the retaining action by the grillage beam on the adjacent soils has not been included. The expected local strengthening mechanism by the grillage beams is not fully represented by the model. Additionally, as the Mohr-Coulomb shear failure criterion cannot capture any plastic deformation induced by a significant increase in mean confining pressure due to the surcharge, it may also have contributed to the smaller predicted deformations.

Comparing the numerical and test responses at the two inclinometers, larger down-slope soil movements are mobilized at I1. This can be attributed to the fact that it is in the immediate vicinity of the surcharge area. Both the simulation and the field test demonstrate that relatively more considerable horizontal displacements are mobilized at a depth of $\sim 1.0 \mathrm{~m}$ below the ground surface at Il as the surcharge pressure is wholly applied. This implies that a bulge-shaped mechanism similar to a bearing capacity failure is developed in the region beneath the slope crest. This may indicate that the soil nails can help provide stabilizing forces to constrain the formation of a deep-seated sliding mass.

Among the three numerical models with nails considered, it can be observed that the different treatments of nail heads has only negligible influence on the displacement profile at I1, whilst relatively more significant discrepancy is shown by the response at I2, despite that the displacements are relatively smaller in magnitude. It can be attributed to the fact that I 2 is mostly located between the two rows of nails, and the local strengthening effect by connecting the nail heads can influence the response at I2 to a more notable extent than that at II. Reasonably the numerical results demonstrate that with stronger constraint of pinning nail heads together, the horizontal movements of soils surrounded by the rows of nails would be smaller in magnitude.

4.2. Nail Force Distribution. Figures 7, 8, and 9 compare the calculated nail forces with the field measurements. Each figure corresponds to one of the three models with different 


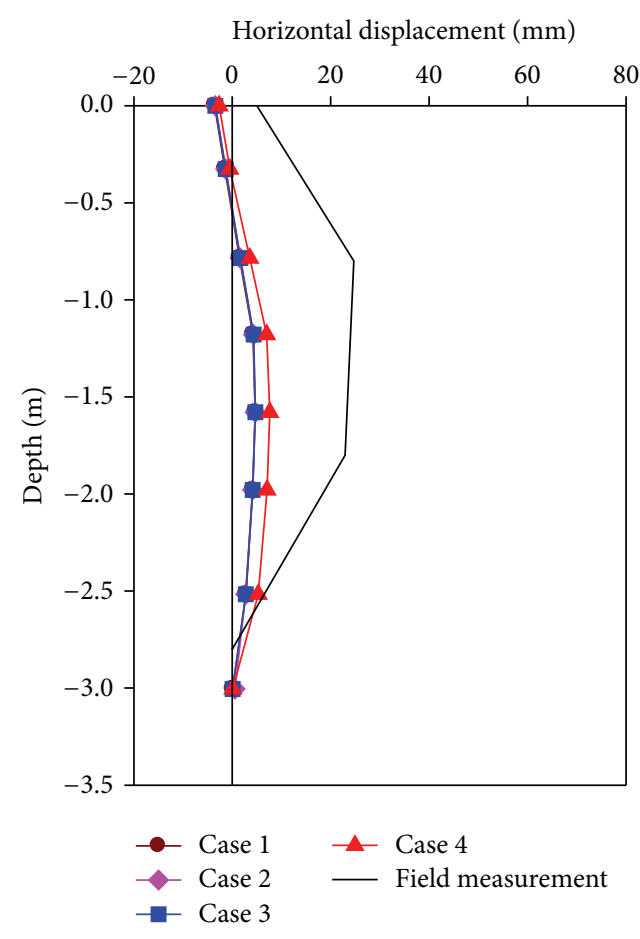

(a) At the end of stage $2\left(q_{s}=49 \mathrm{kPa}\right)$

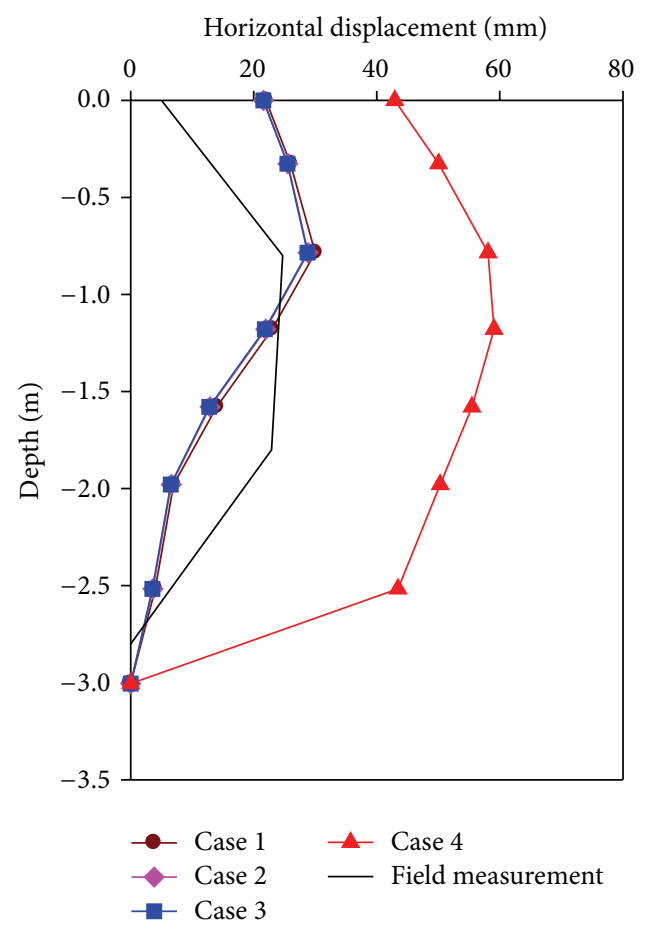

(b) At the end of stage $4\left(q_{s}=72 \mathrm{kPa}\right)$

FIGURE 5: Distribution of horizontal down-slope displacement at I1 at different surcharge stages ( $q_{s}$ denotes the surcharge pressure).

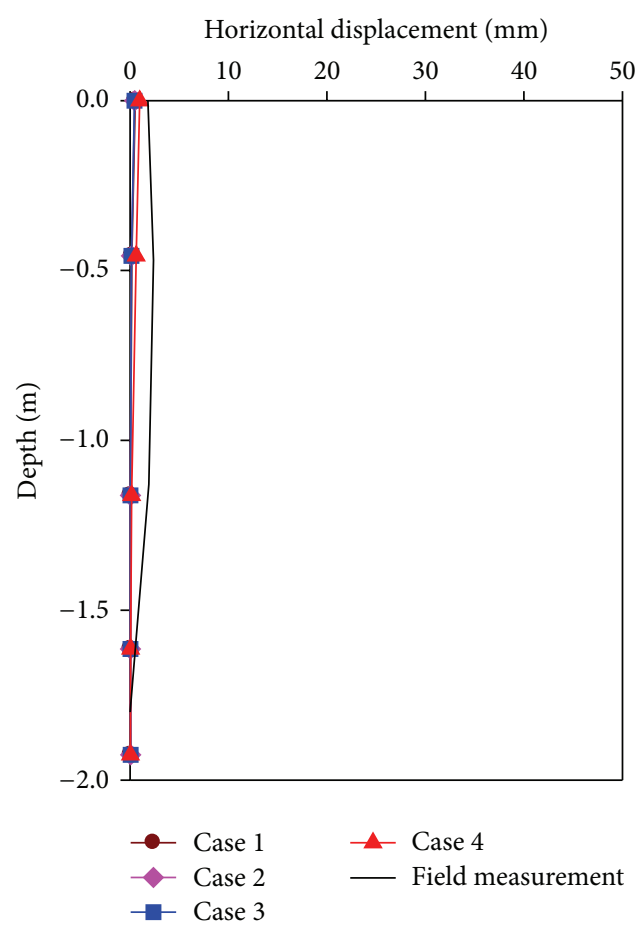

(a) At the end of stage $3\left(q_{s}=49 \mathrm{kPa}\right)$

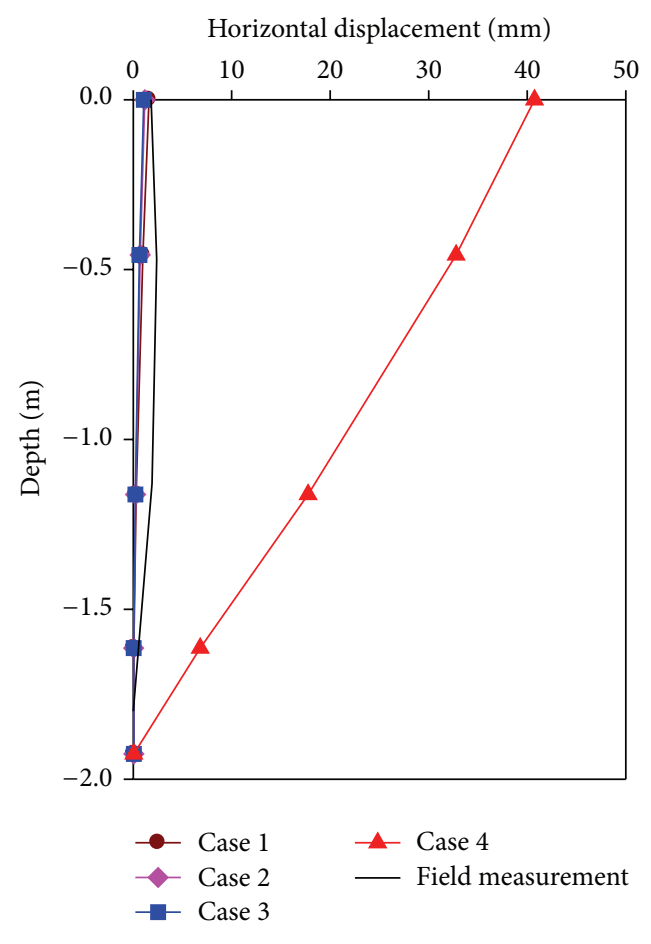

(b) At the end of stage $4\left(q_{s}=72 \mathrm{kPa}\right)$

FIGURE 6: Distribution of horizontal down-slope displacement at I2 at different surcharge stages. 


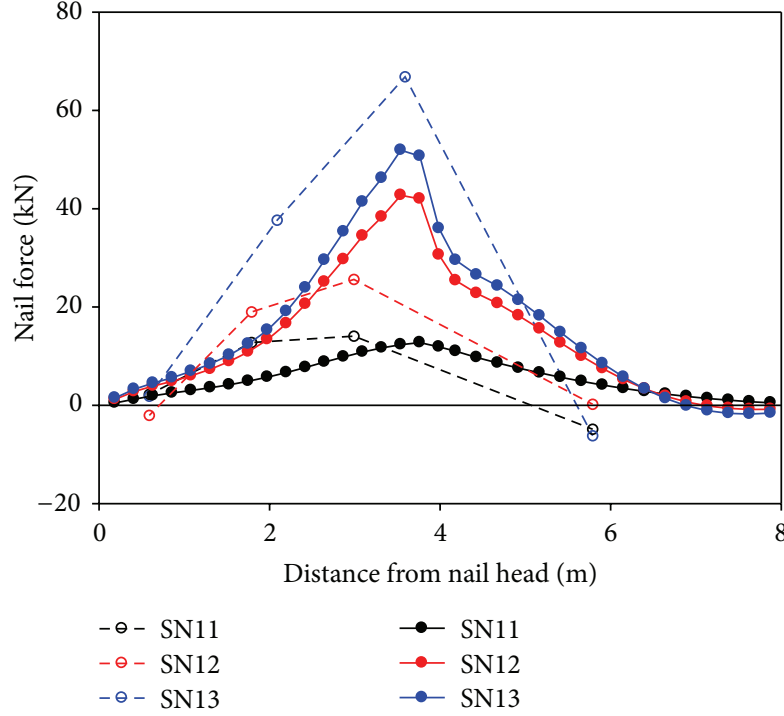

(a) At the upper row of soil nails

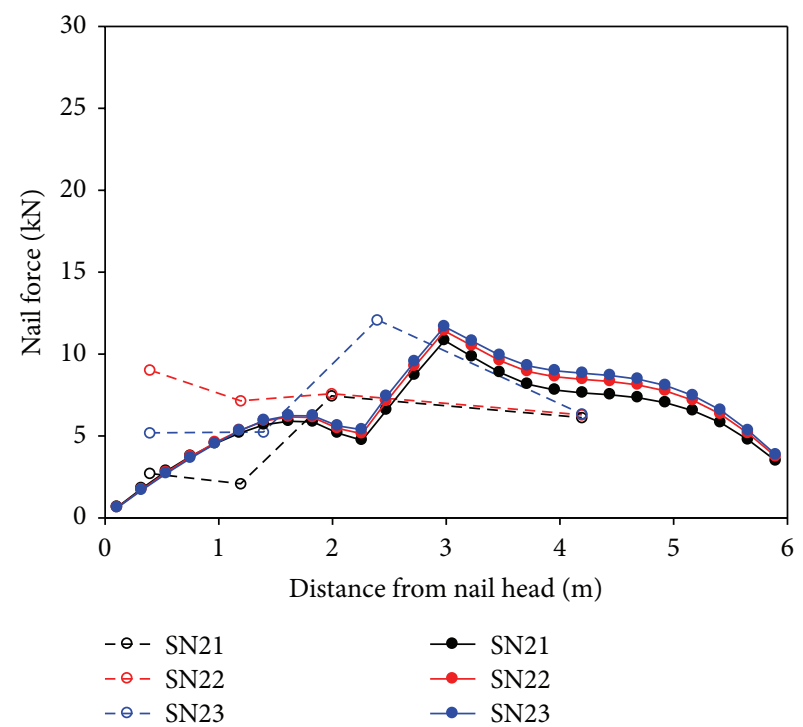

(b) At the lower row of soil nails

Figure 7: Distribution of nail force caused by the surcharge loads (case 1: hollow symbol lines denote field measurements, and solid symbol lines are numerical results).

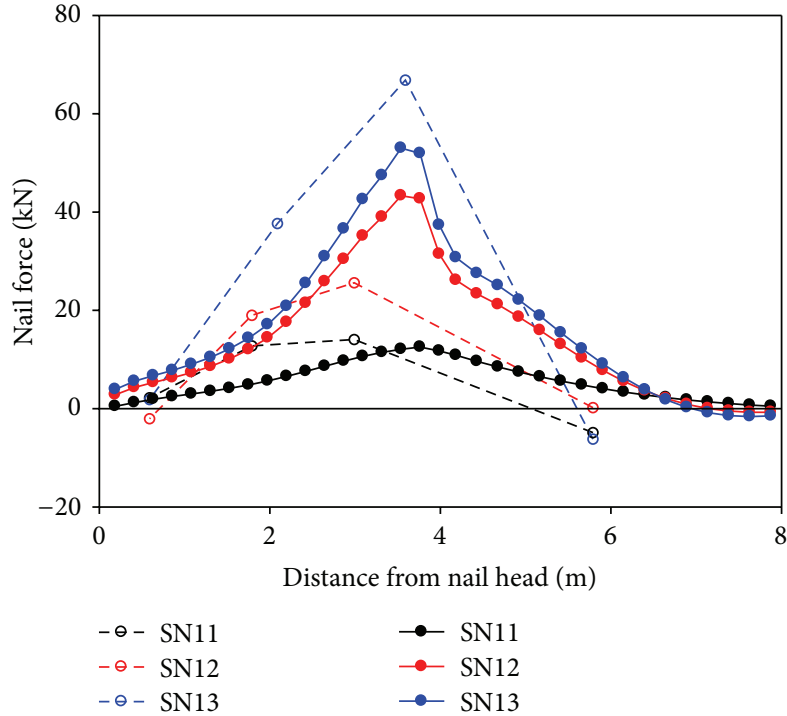

(a) At the upper row of soil nails

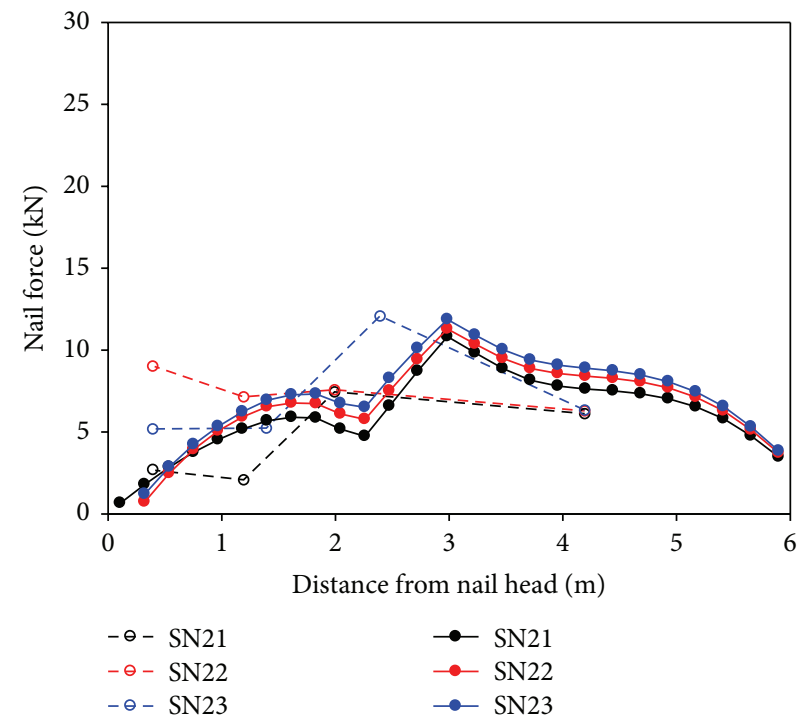

(b) At the lower row of soil nails

FiguRE 8: Distribution of nail force caused by the surcharge loads (case 2: hollow symbol lines denote field measurements, and solid symbol lines are numerical results).

considerations of nail heads. The field measured nail forces were interpreted from the readings of the strain gauges installed on nails SN11 SN15 (upper row) and SN21 SN25 (lower row). The measurements at SN13 and SN23, which were located along the central section (see Figure 1), are directly adopted for comparison. For the other four columns of nails, the measurements of the symmetrically located pair are averaged for comparison considering the symmetry of the test slope. All the three models, despite considering different treatments at the nail heads, predict similar nail force patterns as those observed in the field test. Particularly for the upper rows of soil nail, the numerical results are in good agreement with the field data that relatively larger axial loads would be mobilized in the nail that is located closer to the central section, and a peak value would be mobilized at a nailing depth of about $3.5 \mathrm{~m}$. In contrast, the predictions for the lower rows of soil nails are less dependent on the horizontal distance with the central section for the three cases, which are also shown by the field monitoring data. The distribution patterns of predicted nail force with the nailing depth are also quite similar to the test results. Among the three models, case 3, which models complete constraints of all nail heads, gives 


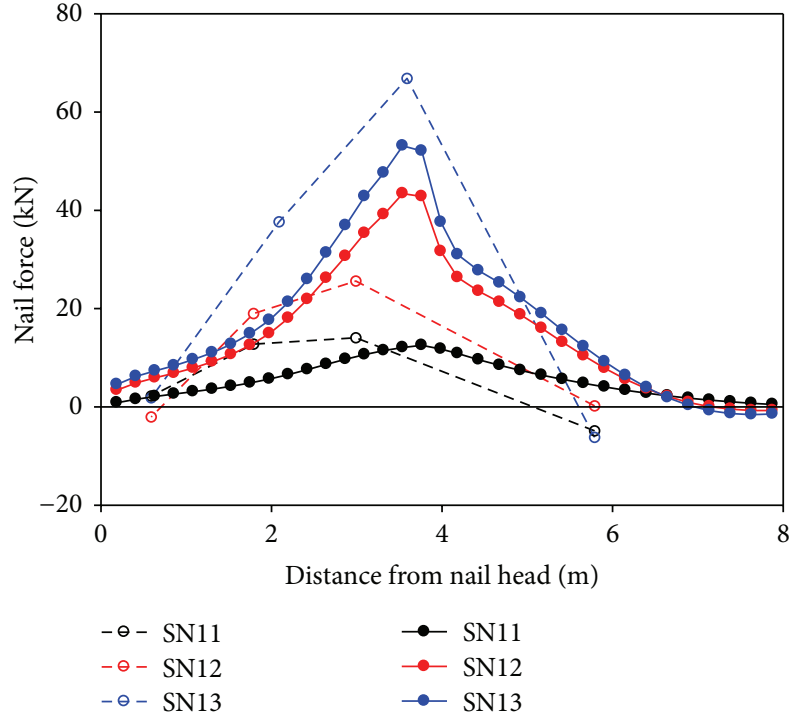

(a) At the upper row of soil nails

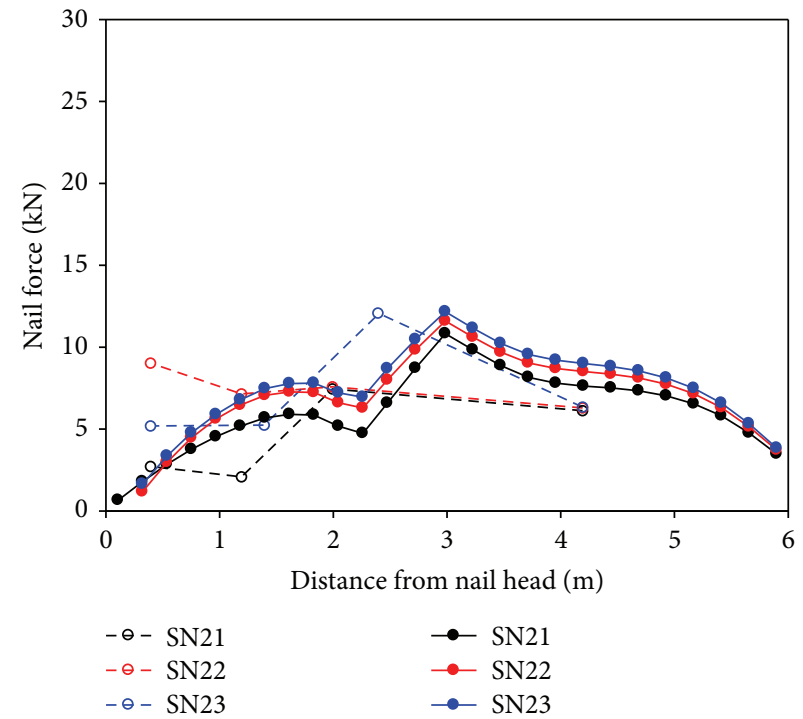

(b) At the lower row of soil nails

FIGURE 9: Distribution of nail force caused by the surcharge loads (case 3; hollow symbol lines denote field measurements, and solid symbol lines are numerical results).

the most notable difference in the axial force response among the lower row of nails and the axial force is larger in the upper portion within the fill slope. This observation can be attributed to the pin-type constraint on all the nail heads and its induced strengthening effect on the interaction between the nails, and the soils in the vicinity of the nail heads. The above comparisons conclude that the developed 3D numerical approach is quite appropriate to model the spatial reinforcement effect of soil nails in the test slope under surcharge loading, and strong dependence of the axial load mobilization is shown by the soil nails in the study slope on the arrangement manner.

Both the numerical results and the field monitoring data illustrate that larger nail forces are mobilized within the upper row of soil nails under the surcharge loading. This is consistent with the relatively larger soil movements (Figures 5 and 6), which also implies greater relative movement along the soil-nail interface. From the 3D representation of the soil-nail interaction, the numerical results show that, for each soil nail, commonly relatively larger normal stress would be mobilized in the interface elements connected to the down face of the nail, which mainly originate from the overburden pressure. Take the results in case 1 as an instance, the maximum normal stress acting on the upper row of three nails are all located at the down face of the middle section, that is, at a buried depth of about $3.5 \mathrm{~m}$, and the complete surcharge pressure induced maximum increase in the normal stress is $226 \mathrm{kPa}, 191 \mathrm{kPa}$, and $10 \mathrm{kPa}$, respectively, for the three nails located from the central section to the side. The difference in the confining stress exerted on the nails would obviously influence the mobilization of nail force and in turn the pull-out resistance of these soil nails.

Although a surface grid structure was present in the field test, which is also modeled in the numerical analyses using a pin-type multiple point constraint, both the test and numerical results demonstrate that only limited tensile force ( $<10 \%$ of the maximum nail force) is mobilized at the heads of the upper row of soil nails. The observation can be explained by the small relative movement along the soil-nail interface near the slope surface and the low confining stress near the slope surface. Differently, a relatively larger ratio of the maximum nail force is mobilized at the head of each nail arranged at a lower position, particularly as shown by the field measurements at the two soil nails near the central section. This can be attributed to the constraint from the surface grillage beams and the induced structural behavior near the heads. The numerical results from the three models considering various conditions at the nail heads also demonstrate that larger nail force can be triggered at the lower rows of nails by the introduction of stronger constraints at the nail heads.

4.3. Moisture Content Redistribution. Although no water entered into the slope during the surcharge process, the moisture probe readings in the field test showed that the water content within the unsaturated fill slope still underwent slight redistributions during the surcharge process [12]. It is found that the numerical results by the above 3D model are consistent with the previous plane strain study results [13], and a good agreement is also achieved between the field and numerical results, both showing a gradually decreasing trend. The capability of the present model in predicting moisture redistribution is verified. For the surcharge stage considered in this paper, the influence of water content redistribution is believed to be negligible on the slope movement as well as the nail force mobilization.

4.4. Spatial Reinforcement of Soil Nails in the Test Slope. To investigate the $3 \mathrm{D}$ reinforcement effect of soil nails on 


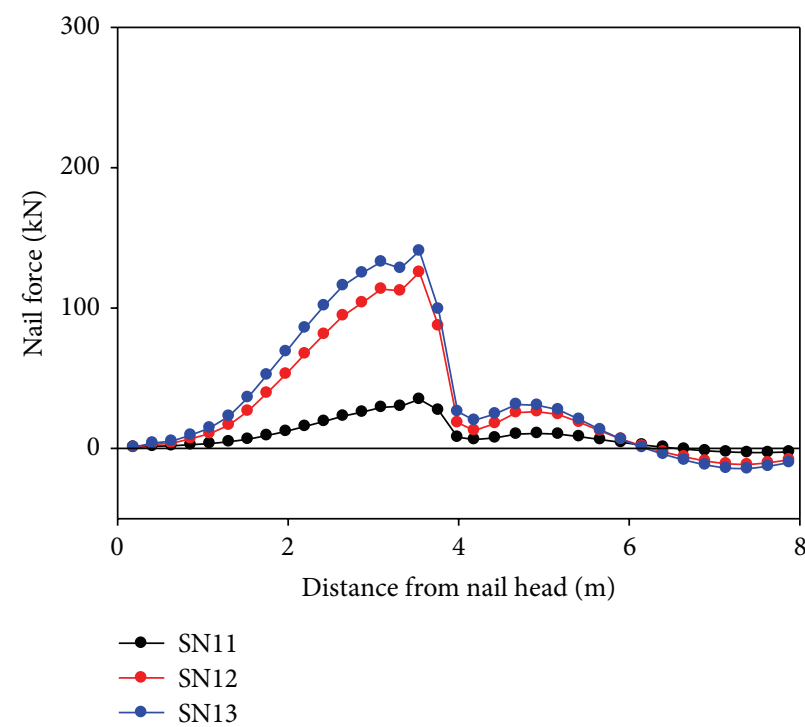

(a) Case 1

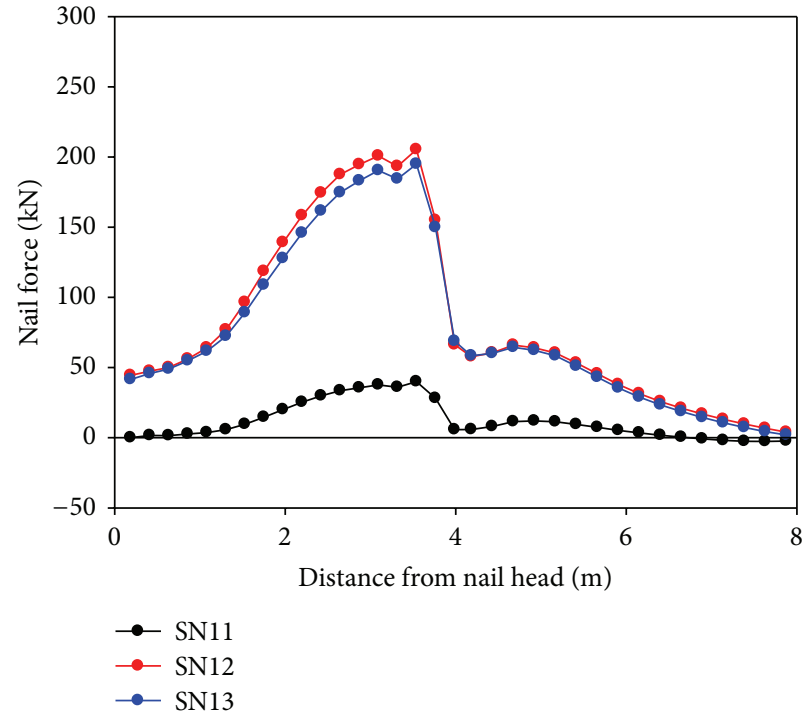

(b) Case 2

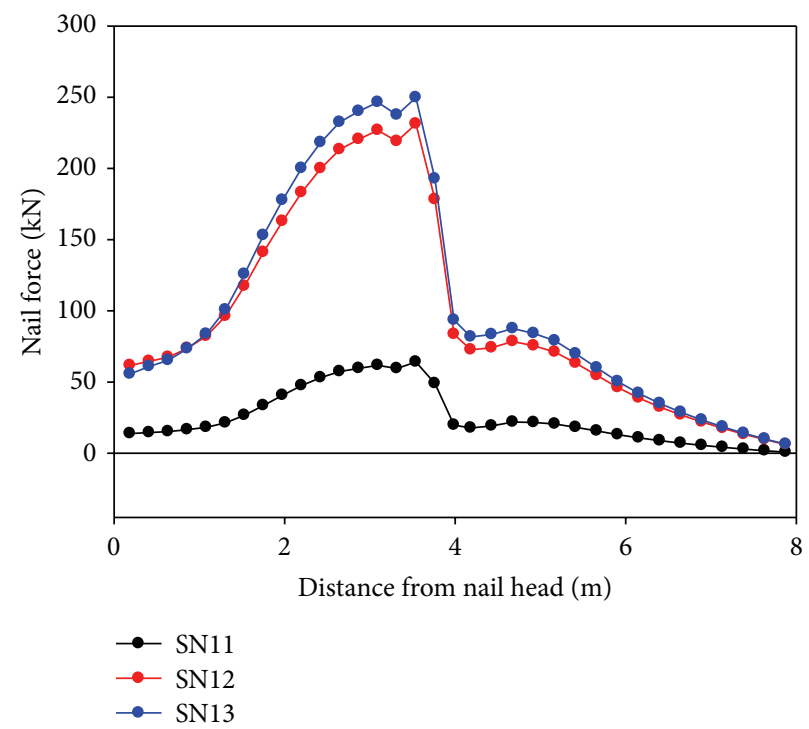

(c) Case 3

FIGURE 10: Comparison of axial force distribution in upper row of soil nails mobilized by an extreme surcharge of $129 \mathrm{kPa}$.

the failure mechanism and bearing capacity of the test slope, a continuous increase of surcharge pressure is simulated for the four slope models in Table 2 until global failure is triggered. It is predicted by the $3 \mathrm{D}$ numerical model that for the unreinforced case, the failure mechanism involves a global sliding plane initiating from the crest of the slope near the surcharge area to the slope toe, which is also quite similar to the previous plane strain study results [13]. The predicted failure occurs at a surcharge of about $82 \mathrm{kPa}$, which is a bit smaller than the results $(138 \mathrm{kPa})$ given by a plane strain analysis. The difference can be caused by the actual 3D loading conditions in the test that the surcharge area only covered two-thirds of the total width of the slope crest. For the other three cases with nail reinforcement considered, the presence of the soil nails significantly increases the rigidity of the soil located below the upper row of nails. Although different constraints at nail heads have been adopted in the models, commonly the failure mechanism consists of a shallow-seated localized plastic zone that originates from the centre of the surcharge area and outcrops near the heads of upper row of nails. A deep-seated zone of large plastic shear strain is also formed near the bottom of the slope, which is where the global failure mechanism of the unreinforced slope is initiated. The development of this shear zone is prohibited by the existence of the two rows of soil nails. The modeling results also show that the surcharge capacity for the three nailed slope models can be increased significantly by the incorporation of the surface structure, which are $129 \mathrm{kPa}$ (case 1), $163 \mathrm{kPa}$ (case 2), and $174 \mathrm{kPa}$ (case 3), respectively.

Figure 10 presents a comparison of the mobilized axial force distributions at a constant surcharge pressure of $129 \mathrm{kPa}$, that is, at the instant of the failure for the nailed slope model 
without consideration of the surface grid structure. The results at the upper row of soil nails are chosen for their vicinity to the surcharge area. It can be seen that, for each nail, a larger peak magnitude of nail force would be mobilized when stronger surface connectivity is considered in the numerical model. Take the nail SN11 near to the lateral side as an instance, the peak force predictions show an obvious increase from $35 \mathrm{kN}$ (case 1) to $64 \mathrm{kN}$ (case 3). It can also be observed from the results that, in case 3 , a notable tensile axial load is triggered at the head of SN11 owing to the simulated constraint by extended grillage beams.

To further examine the spatial reinforcement effect of soil nails in the test slope, a comparison is also made between the modeling results of current 3D model and those from previous plane strain study [13]. It has been demonstrated by the previous results that the incorporation of bond-slip behavior along the soil-nail interface can significantly influence the mobilization of nail force. Particularly, very significant compressive nail forces are calculated for the portion of upper soil nail buried in in situ soils by the plane strain model, even when the possible tangential slippage has been considered, which deviate from the field measurements and are therefore considered to be unrealistic. The current 3D model takes into account the bond-slip along the soil-nail interface. It has been shown above that the predictions of axial force basically remain tensile for all soil nails and are in better agreement with the test results. Furthermore, for a plane strain assumption based model, the soil nails are modeled as two-dimensional flat plates of equivalent cross-sectional area and stiffness, which cannot represent the spatial arrangement of discrete soil nails and in turn the arching effect by two adjacent nails on the upper portion of soils. The above comparison concludes that only the $3 \mathrm{D}$ model presented in this study can reproduce the spatial effect of nail reinforcement in the axial force response as observed in the field test.

\section{Conclusions}

A 3D numerical model has been developed to back-analyze a field slope test. Using the field test data as a reference, a series of numerical analyses have been conducted to examine the spatial reinforcement effect of two rows of ten cement grouted soil nails in the test fill slope. The study focuses on the behavior of the nailed slope under surcharge loading when different treatments of surface grillage structure connecting nail heads are adopted. Similar to previous plane strain analyses, the $3 \mathrm{D}$ modeling results in this study again demonstrate that the presence of the soil nails increases the overall stability of a loose fill slope under surcharge loading. The stabilizing forces mainly come from the upper row of soil nails along which the effective confining pressure is significantly increased due to the surcharge loading. A comparison of nail force distributions between the numerical predictions and the field measurements suggests that the maximum nail force is always mobilized at the middle portion of the nails, corresponding to the depth of the potential global sliding plane.

Both the numerical results and field measurements approve that the axial force response within the two rows of soil nail presents an obvious feature of nonuniform distribution with respect to the spatial arrangements. Relatively larger axial forces are mobilized in the upper row of nails that are closer to the central section and connected by grillage beams at the heads. Different to the previous results by plane strain analyses that the role of a facing structure at the slope surface is of less significance, the numerical results from this study illustrate that the overall response of the nailed slope can be significantly influenced by the various arrangements of surface structure, particularly when an extreme surcharge loading is applied. This is due to the fact that larger slope deformation can be expected when an overburden surcharge is increased near to its capacity, and the multiple point constraint simulating the surface grid structure would impose additional restraint effects on the potential relative displacements at the connected nail heads.

\section{Acknowledgment}

The authors acknowledge the support by the State Key Laboratory of Hydroscience and Engineering (no. 2012-KY-04).

\section{References}

[1] F. Schlosser, "Behaviour and design of soil nailing," in Proceedings of the Recent Developments in Ground Improvement Techniques, pp. 399-413, Bangkok, Thailand, 1982.

[2] N. Gurung and Y. Iwao, "Analytical pull-out model for extensible soil reinforcement," Journal of Geotechnical Engineering, vol. 624, pp. 11-20, 1999.

[3] A. Misra and C.-H. Chen, "Analytical solution for micropile design under tension and compression," Geotechnical and Geological Engineering, vol. 22, no. 2, pp. 199-225, 2004.

[4] W.-H. Zhou and J.-H. Yin, "A simple mathematical model for soil nail and soil interaction analysis," Computers and Geotechnics, vol. 35, no. 3, pp. 479-488, 2008.

[5] L. L. Zhang, L. M. Zhang, and W. H. Tang, "Uncertainties of field pullout resistance of soil nails," Journal of Geotechnical and Geoenvironmental Engineering, vol. 135, no. 7, pp. 966-972, 2009.

[6] T. Matsui, K. C. San, and K. Hayashi, "Design and field test on a reinforced cut slope," in Performance of Reinforced Soil Structures: Proceedings of the International Reinforced Soil Conference, pp. 235-239, Thomas Telford, London, UK, 1990.

[7] C. Y. Cheuk, C. W. W. Ng, and H. W. Sun, "Numerical experiments of soil nails in loose fill slopes subjected to rainfall infiltration effects," Computers and Geotechnics, vol. 32, no. 4, pp. 290-303, 2005.

[8] C.-C. Fan and J.-H. Luo, "Numerical study on the optimum layout of soil-nailed slopes," Computers and Geotechnics, vol. 35, no. 4, pp. 585-599, 2008.

[9] M. Zhang, E. Song, and Z. Chen, "Ground movement analysis of soil nailing construction by three-dimensional (3-D) finite element modeling (FEM)," Computers and Geotechnics, vol. 25, no. 4, pp. 191-204, 1999.

[10] M. Z. Yang and E. C. Drumm, "Numerical analysis of the load transfer and deformation in a soil nailed slope," Geotechnical Special Publication, vol. 96, pp. 102-116, 2000. 
[11] W. Zhou, Experimental and theoretical study on pullout resistance of grouted soil nails [Ph.D. thesis], The Hong Kong Polytechnic University, Hong Kong, China, 2008.

[12] J. Li, Field study of a soil nailed loose fill slope [Ph.D. thesis], The University of Hong Kong, Hong Kong, China, 2003.

[13] Y. D. Zhou, C. Y. Cheuk, and L. G. Tham, "Numerical modelling of soil nails in loose fill slope under surcharge loading," Computers and Geotechnics, vol. 36, no. 5, pp. 837-850, 2009.

[14] ABAQUS Inc, Analysis user's manual, Version 6.10, 2010.

[15] P. Menétrey and K. J. Willam, "Triaxial failure criterion for concrete and its generalization," ACI Structural Journal, vol. 92, no. 3, pp. 311-318, 1995.

[16] E. C. Leong and M. F. Randolph, "Finite element modelling of rock-socketed piles," International Journal for Numerical \& Analytical Methods in Geomechanics, vol. 18, no. 1, pp. 25-47, 1994. 


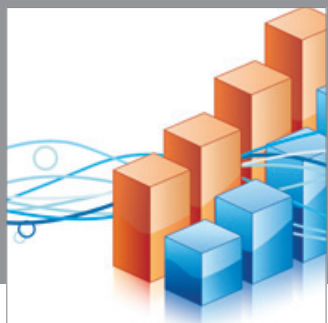

Advances in

Operations Research

mansans

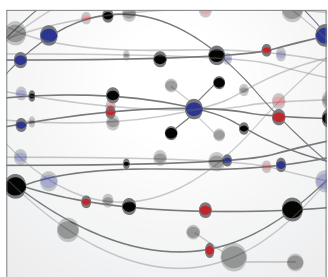

The Scientific World Journal
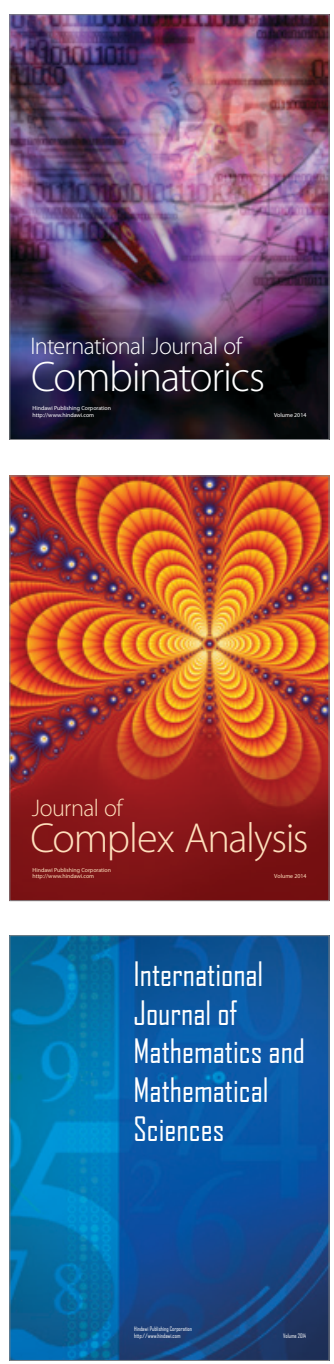
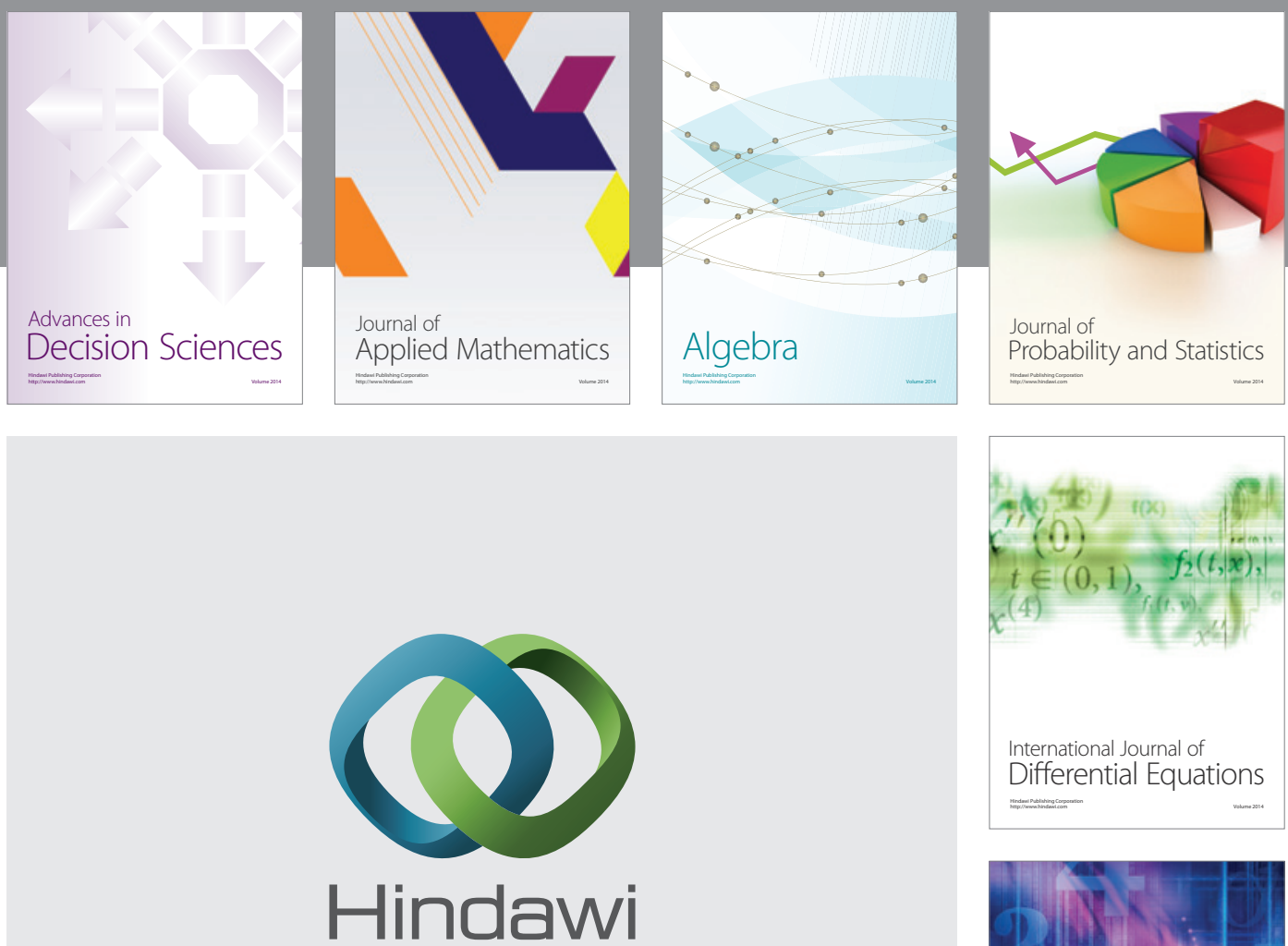

Submit your manuscripts at http://www.hindawi.com
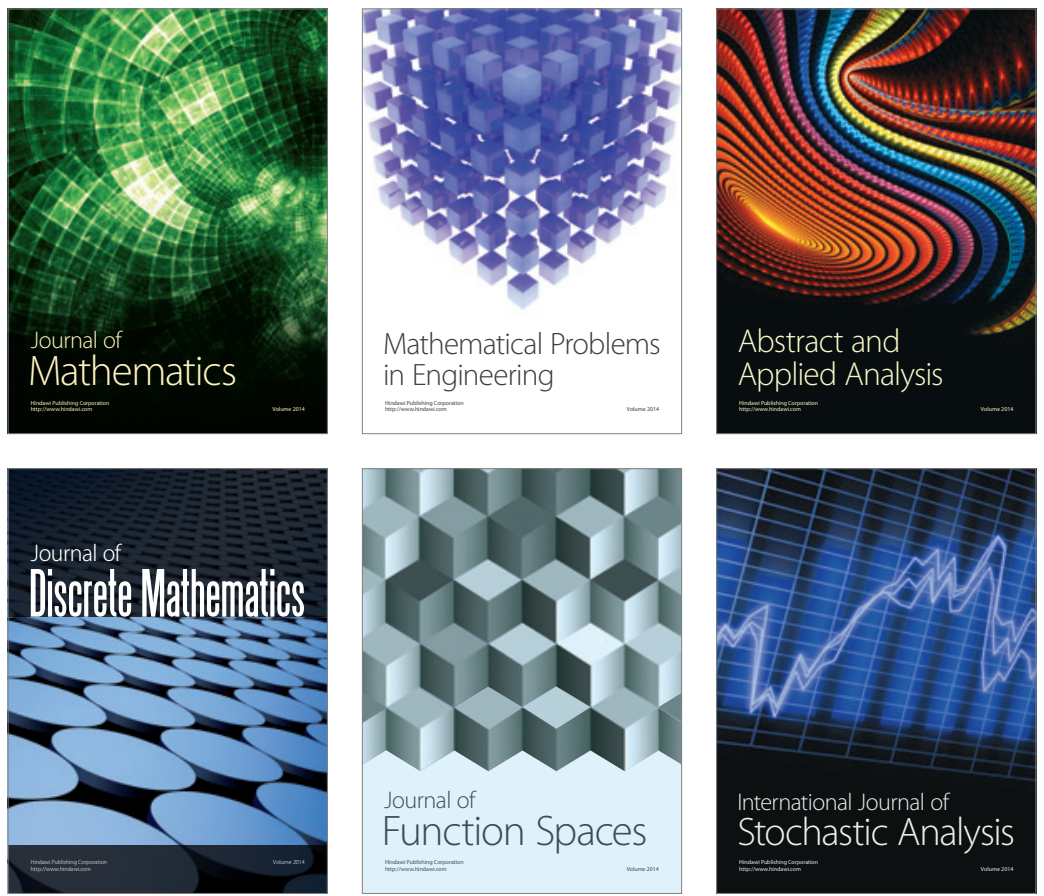

Journal of

Function Spaces

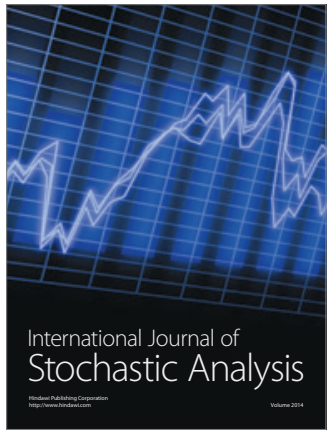

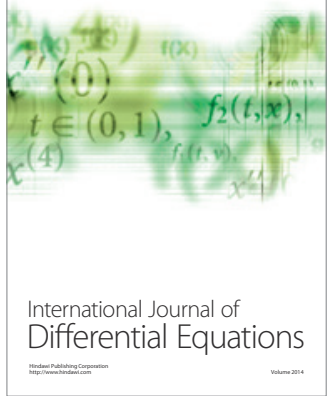
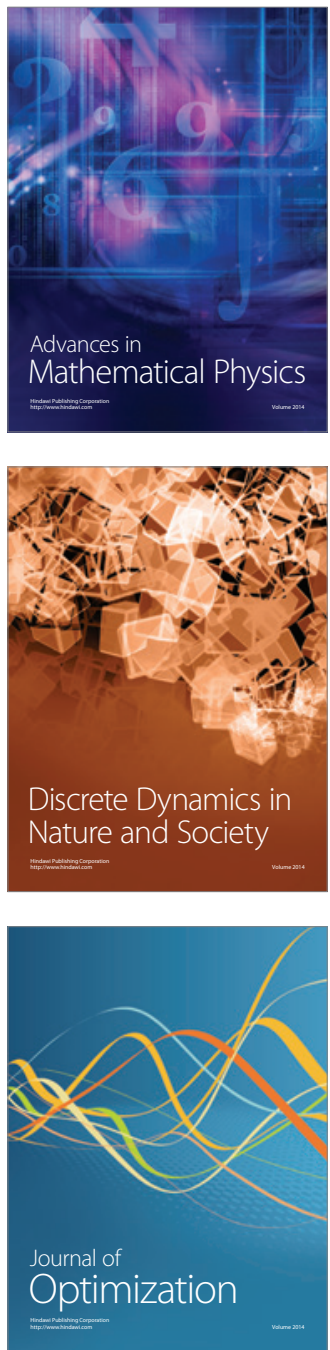